\title{
Correction to: Dependability enhancing mechanisms for integrated clinical environments
}

\author{
Wenbing Zhao' ${ }^{1}$ - Mary Q. Yang ${ }^{2,3}$
}

Published online: 28 May 2018

(C) The Author(s) 2018

\section{Correction to: J Supercomput (2017) 73:4207-4220 https://doi.org/10.1007/s11227-017-2003-0}

Acknowledgements This study was partially supported by United States National Institutes of Health (NIH) Academic Research Enhancement Award 1R15GM114739 and National Institute of General Medical Sciences (NIH/NIGMS) 5P20GM103429, Arkansas Science and Technology Authority (ASTA) Basic Science Research 15-B23 and 15-B-38 and United States Food and Drug Administration (FDA), contract No. HHSF223201510172C and HHSF223201610111C, and by a Graduate Faculty Research Support award from the Office of Research, Cleveland State University. However, the information contained herein represents the position of the author(s) and not necessarily that of the NIH and FDA. An earlier version of this article was presented

The original article can be found online at https://doi.org/10.1007/s11227-017-2003-0.

Mary Q. Yang

mqyang@ualr.edu

Wenbing Zhao

wenbing@ieee.org

1 Department of Electrical Engineering and Computer Science, Cleveland State University, Cleveland, $\mathrm{OH} 44115$, USA

2 Department of Information Science, George Washington Donaghey College of Engineering and Information Technology, Little Rock, AR, USA

3 Joint Bioinformatics Program of University of Arkansas at Little Rock, University of Arkansas for Medical Sciences, 2801 S. University Avenue, Little Rock, AR 72204, USA 
at the IEEE 12th International Conference on Autonomic and Trusted Computing in 2015 [26].

Open Access This article is distributed under the terms of the Creative Commons Attribution 4.0 International License (http://creativecommons.org/licenses/by/4.0/), which permits unrestricted use, distribution, and reproduction in any medium, provided you give appropriate credit to the original author(s) and the source, provide a link to the Creative Commons license, and indicate if changes were made. 